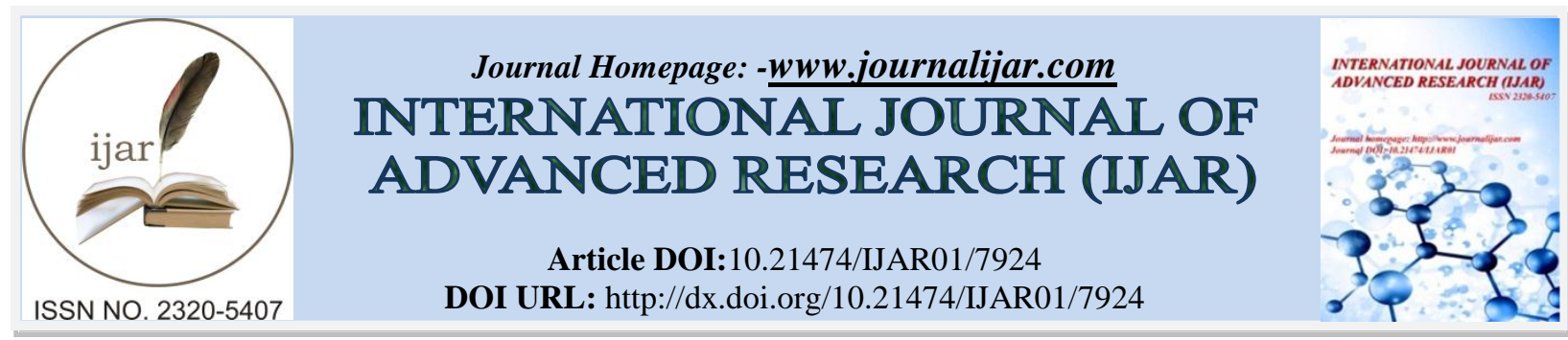

RESEARCH ARTICLE

\title{
RARE PRESENTATION OF AREOLAR SEBACEOUS HYPERPLASIA.
}

\section{Reem H. Alenazi ${ }^{1}$ and Sara Qari ${ }^{2}$.}

1. Faculty of Medicine, King Abdulaziz University, Saudi Arabia (Medical Intern).

2. Department of Dermatology, Faculty of Medicine, King Abdulaziz University, Saudi Arabia.

\section{Manuscript Info}

Manuscript History

Received: 14 August 2018

Final Accepted: 16 September 2018

Published: October 2018

\section{Abstract}

A 56-year-old woman reported the appearance of a lesion in both breasts characterized by the presence of yellowish thickening of the areolae with the presence of papules and nodules. The mammography didn't show an underlying malignant lesions and the biopsy concluded to Montgomery tubercles.

Copy Right, IJAR, 2018,. All rights reserved.

\section{Introduction:-}

\section{Background}

Sebaceous hyperplasia is a common disorder of sebaceous gland that occurs mainly in newborns $[1,2]$ and ageing adults, with no particular predilection according to gender [3]. The majority of the cases reported by literature are localized in the area with the largest sebaceous glands; like the face [4], the chest [5] or the back. Less common localizations were described, like the hyperplasia of Tyson glands in the clitoris [6] or the hyperplasia of Montgomery glands in the areola [7]. The diagnosis of this condition is made by its clinical and histological aspects. This lesion is made of asymptomatic pink or yellow papules, sometimes forming a thickening of the skin [8]. Herein, we describe a case of a bilateral areolar sebaceous hyperplasia (ASH) in a 56-year-old woman.

\section{Case report}

A 56-year-old woman reported the appearance of bilateral recurrent papules of the areolae and nipples with a yellow discoloration of this area's skin and sometimes the presence of black comedones.

These symptoms began 10 years ago, but the patient did not consult except recently because of her fear of cancer. The patient had a family history of breast cancer; diagnosed in two of her sisters, one of whom died. The patient had a 60 pack-year history of smoking and she was obese with a BMI of $32.39 \mathrm{~kg} / \mathrm{m}^{2}$. The physical exam of the breasts revealed the presence of yellowish thickening of both areolae and nipples with multiple papules and nodules. The pressure on the lesion expressed a whitish material. The remainder of her physical examination was without any other particularities. A mammography was performed and showed multiple simple cysts as well as benign appearing solid nodules predominately within the left breast. Targeted ultrasound of these areas confirm the presence of multiple and solid nodules. Scattered bilateral calcifications were noticed. A skin punch biopsy concluded to the diagnosis of Montgomery's tubercles. No treatment was recommended and it has been decided that the patient should receive an annual screening. 


\section{Discussion:-}

The first case of sebaceous hyperplasia of the areola described in the literature was reported by Catalano in 1985 [9]. Since that date, few cases have been published; 10 cases in females and 6 cases in males in total [7, 9-22]. Therefore, there is no consensus about the exact microscopic features of this entity. The areola which is the area of the epidermis that surrounds the nipple contains many buds of sweat glands and apocrine sebaceous glands [23]. First described by Perkin [24], the sebaceous glands of the areola and nipple could undergo structural changes under the effect of hormones, mainly androgenic and estrogenic hormones. Those changes can lead to the development of a benign condition called sebaceous hyperplasia. The etiopathogenesis of ASH is still not well elucidated and other factors were incriminated as risk factors of this disease as ageing, family history or exposure to cyclosporine [2529]. Different microscopic features were described in cases of areolar sebaceous hyperplasia. Some authors describe it as the hyperplasia of Montgomery gland while others describe it as it as the hyperplasia of independent sebaceous gland of the skin of the areola and nipple.

There are two explanations for this disagreement, first, the hyperplasia of Montgomery glands is generally observed in women during the pregnancy under the influence of an increase in the level of estrogen hormones, clinically they appear as reddish papules, whereas the hyperplasia of sebaceous gland is related to the level of androgenic hormones and appears as yellowish papules [30]. Second, so far there is no agreement about the very nature of Montgomery tubercles [31]. Although there is not yet a consensus about the histopathological definition of this entity, the areolar sebaceous hyperplasia in male or female, can be defined as the result of the increase in the number of sebaceous cells forming one lump under the upper dermis and opening to the surface through a duct $[15,32]$.

Nevertheless, more studies are needed to give a definitive answer on the question that arises about the cellular nature of these glands.

The evolution of this lesion is characterized by stabilization then a resolution with time [3]. No specific treatment is indicated in ASH Unlike Fordyce disease which is a similar lesion of ectopic sebaceous glands that frequently involves an inflammation mechanism [33]. In literature some cases were treated surgically or by photodynamic therapy [34]. Recently another therapy, the isotretinoin has proven its efficacy in reducing the size of sebaceous glands [35, 36]. Although it is a benign condition the search for an underlying malignant tumor is systematic [37]. Hence it is preferable that the patient has a regular monitoring of his lesion, especially in the case where there is a family history of cancer like the patient of our case. 


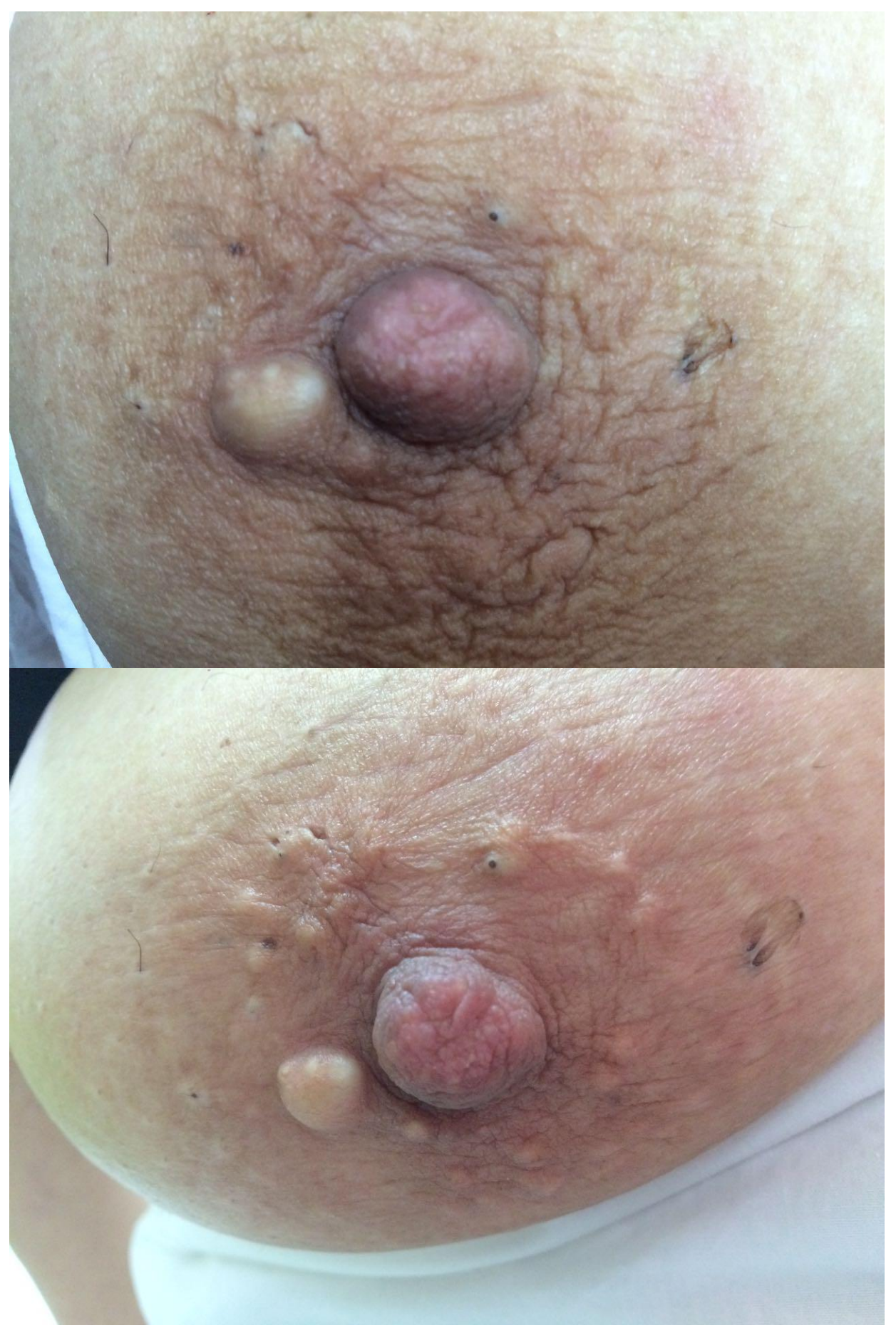




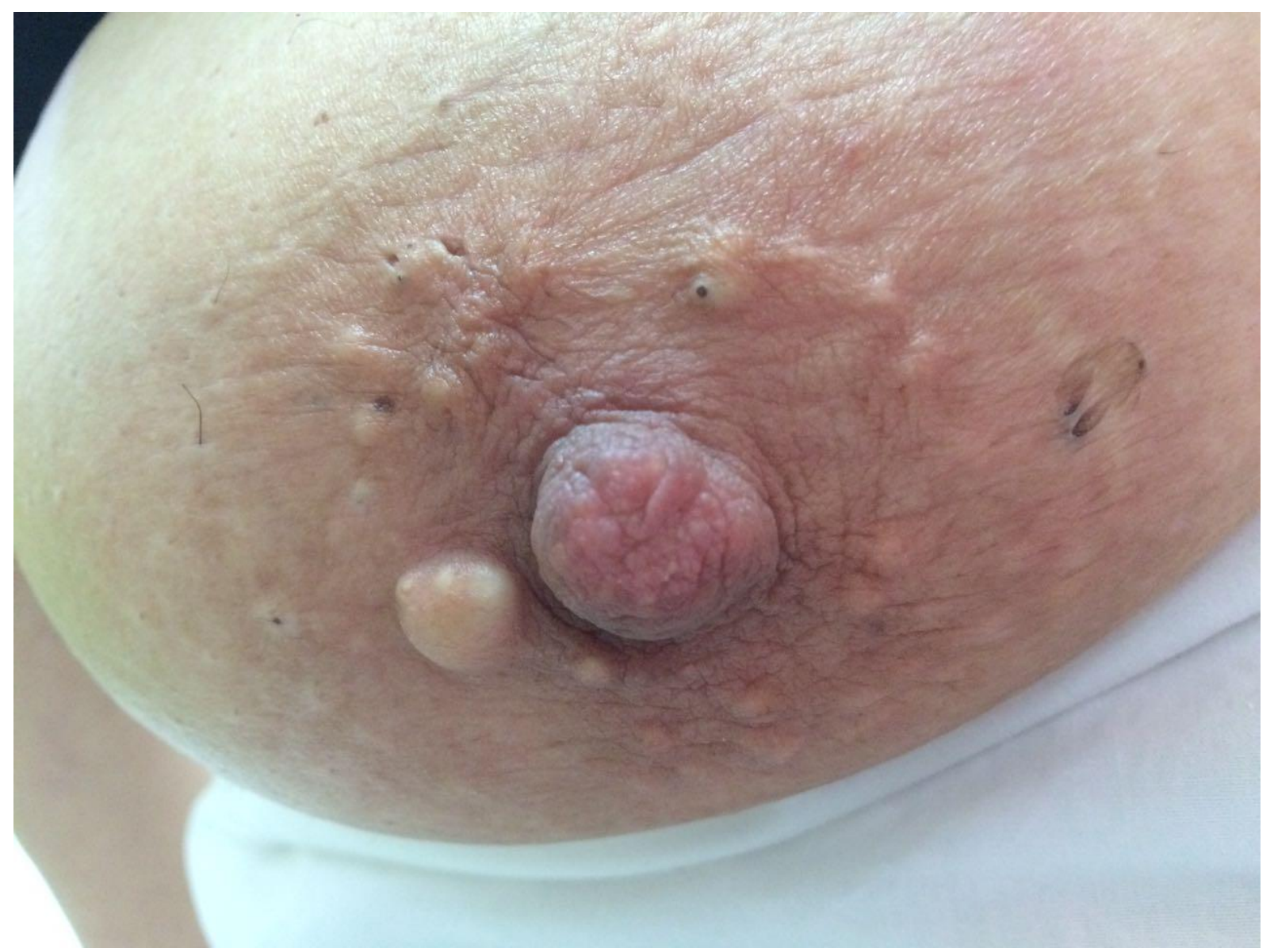




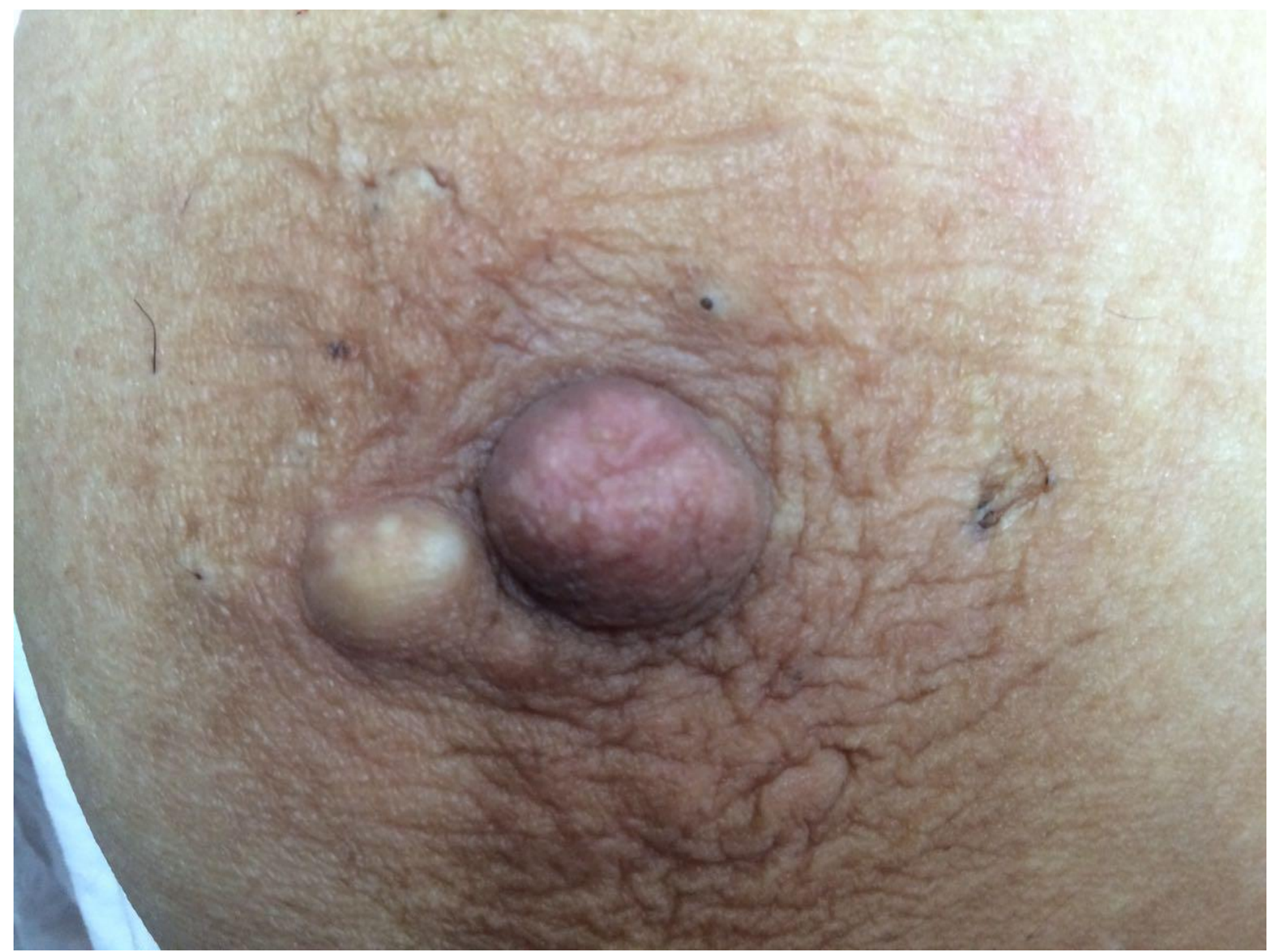

\section{References:-}

1. Kanada KN, Merin MR, Munden A, Friedlander SF. A prospective study of cutaneous findings in newborns in the United States: correlation with race, ethnicity, and gestational status using updated classification and nomenclature. J Pediatr. 2012 Aug. 161(2):240-5.

2. Moosavi Z, Hosseini T. One-year survey of cutaneous lesions in 1000 consecutive Iranian newborns. Pediatr Dermatol. 2006 Jan-Feb. 23(1):61-3

3. Brzezinski P, Chiriac A. Sebaceous hyperplasia in neonates and adults. Our Dermatol Online. 2015;6(1):107108.

4. Engel F, Ellero B, Woehl-Jaegle ML, Cribier B. Diffuse sebaceous hyperplasia of the face induced by cyclosporine. Ann Dermatol Venereol. 2005 Apr;132(4):342-5.

5. Sato T, Tanaka M.Linear sebaceous hyperplasia on the chest. Dermatol Pract Concept. 2014 Jan 31;4(1):93-5

6. Roma AA, Barry J, Pai RK, Billings SD.Sebaceous hyperplasia of the vulva: a series of cases reporting no association with the Muir-Torre syndrome. Int J Gynecol Pathol. 2014 Jul;33(4):437-42.

7. Lester RA, Torgerson RR, Sandhu NP. Rare presentation of sebaceous hyperplasia. BMJ Case Reports. 2014;2014:bcr2014204025. doi:10.1136/bcr-2014-204025.

8. Zouboulis CC. Acne and sebaceous gland function. Clin Dermatol. 2004 Sep-Oct;22(5):360-6.

9. Catalano PM, Ioannides G. Areolar sebaceous hyperplasia. J Am Acad Dermatol 1985;13:867-868.

10. Krisp A, Krause W. Areolar sebaceous hyperplasia. Acta Derm Venereol. 2003;83:61-2.

11. Sánchez Yus E, Montull C, Valcayo A, et al. Areolar sebaceous hyperplasia: a new entity?. J Cutan Pathol 1988;15:62-3.

12. Hammerton MD, Shrank AB. Superficial sebaceous hyperplasia of the areolae. Br J Dermatol 1993;129:64950.

13. Tsuji T, Yamauchi R. Areolar sebaceous hyperplasia with a Fordyce's spot-like lesion. J Dermatol 1994;21:524-6.

14. Belinchón I, Aguilar A, Tardío J, et al. Areolar sebaceous hyperplasia: a case report. Cutis 1996;58:63-4. 
15. Fariña MC, Soriano ML, Escalonilla $\mathrm{P}$, et al. Unilateral areolar sebaceous hyperplasia in a male. Am $\mathrm{J}$ Dermatopathol 1996;18:417-19.

16. Kondo-Morita A, Murata S, Murakami T, et al. Bilateral areolar sebaceous hyperplasia in a male. J Dermatol 2001;28:172-3.

17. Bajaj V, Barrett P, Sripathy T, et al. Areolar sebaceous hyperplasia in a male: a different morphology. J Cutan Pathol 2007;34:207-8.

18. Conde-Taboada A, De la Torre C, Mayo E, et al. Unilateral areolar sebaceous hyperplasia in a male. J Eur Acad Dermatol Venereol 2007;21:120-1.

19. Guillermo N, Peñate Y, Soler E, et al. Bilateral areolar sebaceous hyperplasia in a female. Int J Dermatol 2008;47:1214-15.

20. Tulbert B, Brodell RT. A simple and effective treatment for ectopic sebaceous glands on the areola. Dermatol Surg 2010;36:1332-5.

21. Fernandez-Flores A, Valerdiz S, Crespo LG, et al. Areolar sebaceous hyperplasia with underlying primary duct carcinoma of the breast in a woman with Donohue syndrome (leprechaunism). Am $\mathbf{J}$ Dermatopathol 2012;34:e15-18.

22. Errichetti E, Piccirillo A, Viola L, et al. Areolar sebaceous hyperplasia associated with oral and genital Fordyce spots. J Dermatol 2013;40:670.

23. Zucca-Matthes G, Urban C,3 Vallejo A. Anatomy of the nipple and breast ducts. Gland Surg. 2016 Feb; 5(1): 32-36.

24. Perkins OC, Miller AM. Sebaceous glands in the human nipple. Am J Obstet Gynecol 1926; 11: 789 - 794

25. Zouboulis CC, Boschnakow A. Chronological ageing and photoageing of the human sebaceous gland. Clin.Exp.Dermatol. 2001;26:600-7.

26. Weisshaar E, Schramm M, Gollnick H. Familial nevoid sebaceous gland hyperplasia affecting three generations of a family. Eur J Dermatol. 1999;9:621-3.

27. Kumar P, Marks R. Sebaceous gland hyperplasia and senile comedones: a prevalence study in elderly hospitalized patients. Br J Dermatol. 1987;117:231-6

28. Pang SM, Chau YP. Cyclosporin-induced sebaceous hyperplasia in renal transplant patients.Ann Acad Med Singapore. 2005;34:391-3.

29. Grillo E, Pérez-Gala S, Vano-Galván S, Jaén-Olasolo P. Multiple sebaceous hyperplasia secondary to ciclosporin in a heart transplant patient. Med Clin (Barc) 2013; 141: e3.

30. Blech H, Friebe K, Krause W. Inflammation of Montgomery Glands. Acta dermato-venereologica. 2004;( 84): 93-4.

31. Tavassoli FA, Eusebi V. Tumors of the mammary gland. In: Silverberg SG, Gardner WA, Sobin LH, eds. AFIP Atlas of Tumor Pathology. $4^{\text {th }}$ series, fascicle 10. Washington, DC: American Registry of Pathology, 2009; 810: 371-81.

32. Requena L, Requena C. Glándulassebáceas ectópicas: condición de Fordyce y corpúsculos de Montgomery. En: Neoplasiasanexialescutáneas, 2004: 375-380.

33. Yost J, Robinson M, Meehan SA. Fox-Fordyce disease. Dermatol Online J. 2012 Dec 15;18(12):28.

34. Gold MH, Bradshaw VL, Boring MM, Bridges TM, Biron JA, Lewis TL. Treatment of sebaceous gland hyperplasia by photodynamic therapy with 5-aminolevulinic acid and a blue light source or intense pulsed light source. J Drugs Dermatol. 2004;3:S6-S9.

35. Tagliolatto S, Santos O de O, Alchorne MM de A, Enokihara MY. Sebaceous hyperplasia: systemic treatment with isotretinoin. Anais Brasileiros de Dermatologia. 2015;90(2):211-215. doi:10.1590/abd18064841.20153192.

36. Papakonstantinou E, Aletras AJ, Glass E, Tsogas P, Dionyssopoulos A, Adjaye J,et al. Matrix metalloproteinases of epithelial origin in facial sebum of patients withacne and their regulation by isotretinoin. $\mathrm{J}$ Invest Dermatol. 2005 Oct;125:673-84.

37. Fernandez-Flores A; Valerdiz S; Luis G. Crespo; Rodriguez-Cernuda P. Areolar Sebaceous Hyperplasia with Underlying Primary Duct Carcinoma of the Breast in a Woman with Donohue Syndrome (Leprechaunism). Am J Dermatopathol. 2012 Apr;34(2):e15-8. 